\title{
Cerebrolysin improves cognitive performance in rats after mild traumatic brain injury
}

\author{
Yanlu Zhang, MS, MD,1 Michael Chopp, PhD, ${ }^{2,3}$ Yuling Meng, PhD, ${ }^{1}$ Zheng Gang Zhang, MD, PhD, ${ }^{2}$ \\ Edith Doppler, PhD, ${ }^{4}$ Stefan Winter, PhD, ${ }^{4}$ Timothy Schallert, PhD, ${ }^{5}$ Asim Mahmood, MD, ${ }^{1}$ \\ and Ye Xiong, MD, PhD ${ }^{1}$
}

\begin{abstract}
1 Departments of Neurosurgery and 2Neurology, Henry Ford Hospital, Detroit, Michigan; ${ }^{3}$ Department of Physics, Oakland University, Rochester, Minnesota; ${ }^{4} \mathrm{Clinical}$ Research and Pharmacology, EVER Neuro Pharma GmbH, Unterach, Austria; and ${ }^{5}$ Department of Psychology and Institute for Neuroscience, University of Texas at Austin, Texas
\end{abstract}

\begin{abstract}
OBJECT Long-term memory deficits occur after mild traumatic brain injuries (mTBIs), and effective treatment modalities are currently unavailable. Cerebrolysin, a peptide preparation mimicking the action of neurotrophic factors, has beneficial effects on neurodegenerative diseases and brain injuries. The present study investigated the long-term effects of Cerebrolysin treatment on cognitive function in rats after MTBI.
\end{abstract}

METHODS Rats subjected to closed-head mTBI were treated with saline $(n=11)$ or Cerebrolysin $(2.5 \mathrm{ml} / \mathrm{kg}, n=11)$ starting 24 hours after injury and then daily for 28 days. Sham animals underwent surgery without injury $(n=8)$. To evaluate cognitive function, the modified Morris water maze (MWM) test and a social odor-based novelty recognition task were performed after mTBI. All rats were killed on Day 90 after $\mathrm{mTBI}$, and brain sections were immunostained for histological analyses of amyloid precursor protein (APP), astrogliosis, neuroblasts, and neurogenesis.

RESULTS Mild TBI caused long-lasting cognitive memory deficits in the MWM and social odor recognition tests up to 90 days after injury. Compared with saline treatment, Cerebrolysin treatment significantly improved both long-term spatial learning and memory in the MWM test and nonspatial recognition memory in the social odor recognition task up to 90 days after $\mathrm{mTBI}(\mathrm{p}<0.05)$. Cerebrolysin significantly increased the number of neuroblasts and promoted neurogenesis in the dentate gyrus, and it reduced APP levels and astrogliosis in the corpus callosum, cortex, dentate gyrus, CA1, and CA3 regions $(\mathrm{p}<0.05)$.

CONCLUSIONS These results indicate that Cerebrolysin treatment of mTBI improves long-term cognitive function, and this improvement may be partially related to decreased brain APP accumulation and astrogliosis as well as increased neuroblasts and neurogenesis.

http://thejns.org/doi/abs/10.3171/2014.11.JNS14271

KEY WORDS amyloid precursor protein; Cerebrolysin; cognitive function; mild closed head injury; neuroblast; neurogenesis; traumatic brain injury

$\mathrm{T}$ RAUMATIC brain injury (TBI) is a leading cause of death and disability worldwide. An estimated $75 \%-$ $90 \%$ of the 1.7 million TBI-related emergency room visits in the US each year are a result of mild TBI (mTBI). ${ }^{15}$ Unlike moderate and severe TBI, patients with mTBI may show cognitive impairment in the absence of obvious tissue lesions in the brain. ${ }^{22,94}$ Some patients with mTBI have a measurable cognitive deficit at 1 year. ${ }^{74}$ Recent evidence suggests that an mTBI sustained in early life can interact with the aging process and reduce memory performance many years or decades later. ${ }^{69}$ The pathologies underlying $\mathrm{mTBI}$ are poorly understood and treatment modalities are essentially absent. Investigation of mechanisms underlying mTBI-induced cognitive impairment and development of effective early interventions to mitigate the sequelae of mTBI are required to better understand its pathophysiology and to reduce the burden and incidence of long-term effects of mTBI.

ABBREVIATIONS APP = amyloid precursor protein; $\mathrm{BrdU}=$ 5' $^{\prime}$-bromo-2' -deoxyuridine; $\mathrm{BSA}=$ bovine serum albumin; $\mathrm{DCX}=$ doublecortin; GFAP = glial fibrillary acidic protein; MWM = Morris water maze; $\mathrm{mTBI}=$ mild TBI; NeuN = neuronal nuclei; PBS = phosphate-buffered saline; sAPP $\alpha=$ soluble $\alpha$ form of APP; TBI = traumatic brain injury. SUBMITTED February 4, 2014. ACCEPTED November 18, 2014.

INCLUDE WHEN CITING Published online January 23, 2015; DOI: 10.3171/2014.11.JNS14271.

DISCLOSURE This work was funded by EVER Neuro Pharma GmbH, the manufacturer of Cerebrolysin. Edith Doppler and Stefan Winter are employees of EVER Neuro Pharma GmbH in the Clinical Research and Pharmacology department. 
Cerebrolysin (EVER Neuro Pharma $\mathrm{GmbH}$ ) is a neuropeptide preparation of low-molecular-weight neuropeptides derived from purified brain proteins by standardized enzymatic proteolysis, with neuroprotective and neurotrophic properties similar to naturally occurring growth and neurotrophic factors. ${ }^{79}$ Cerebrolysin reduces neuronal dysfunction by maintaining the integrity of neurons under adverse conditions ${ }^{97}$ and increases neurogenesis, thereby improving functional outcome after stroke in rats. ${ }^{102}$ Early treatment (i.e., 5-60 minutes postinjury) with intracerebroventricular infusion of Cerebrolysin reduces bloodbrain barrier permeability and brain edema and improves functional recovery in a stab-wound rat model of TBI. ${ }^{85}$ The efficacy and safety of Cerebrolysin have been demonstrated in recent clinical trials including stroke, TBI, and Alzheimer's disease. ${ }^{3,6} \mathrm{~A}$ recent clinical trial showed that Cerebrolysin improves cognitive function in patients with mTBI 3 months after injury. ${ }^{8}$ These results indicate that Cerebrolysin has potential as a treatment for brain injuries. Although human studies of Cerebrolysin on TBI are already underway, the mechanisms underlying the beneficial effects remain unknown and cannot be directly investigated in the clinical setting, especially after mTBI. In addition most, if not all, clinical trials for TBI involve moderate to severe injury, ${ }^{57}$ and despite the high frequency of mTBI and cognitive impairment, it is the least wellstudied. ${ }^{18}$ Development of novel therapeutic treatments for mTBI depends on understanding the mechanisms underlying cognitive impairment after mTBI and identifying therapeutic targets in clinically relevant models of mTBI.

Our previous 14-day study demonstrated that posttraumatic treatment with Cerebrolysin improves functional recovery in rats after moderate closed-head TBI. ${ }^{105}$ However, the beneficial effects of Cerebrolysin have not been investigated in animal models of mild closed-head TBI, especially during a long-term (90-day) functional recovery. Considering that the majority of TBIs in patients are mild, we used a well-established, clinically relevant, Marmarou impact acceleration rat model ${ }^{4,21,62}$ to induce closed-head mTBI and to investigate the long-term effects of Cerebrolysin on cognitive function and the potential mechanisms underlying the beneficial effects.

\section{Methods}

All experimental procedures were approved by the Institutional Animal Care and Use Committee of Henry Ford Health System. We designed and performed the experiments to comply with the Stroke Therapy Academic Industry Roundtable recommendations, including method of blinding, study group randomization, and power and statistical analyses ${ }^{49,55}$ To prevent potential biases of performance and detection, the persons who performed the experiments, collected data, and assessed outcome were blinded throughout the course of the experiments and were unaware of the treatment allocation.

\section{Mild TBI Model}

The Marmarou impact acceleration device (Custom Design \& Fabrication South, LLC) was used to induce mTBI in male Wistar rats weighing $388 \pm 9 \mathrm{~g}$ (Charles River Breeding Co.). ${ }^{62,105}$ The animals went through an appropriate pe- riod (1 week) of quarantine and acclimation. Anesthesia in the rats was initially induced with $4 \%$ isoflurane and maintained with $1.0 \%-1.5 \%$ isoflurane in $70 \% \mathrm{~N}_{2} \mathrm{O}$ and $30 \%$ $\mathrm{O}_{2}$ throughout the surgical period. Rectal temperature was maintained at $37^{\circ} \mathrm{C} \pm 0.5^{\circ} \mathrm{C}$ throughout the surgical procedure using a feedback-regulated water heating system. The skin over the cranial vault was shaved and swabbed with Betadine and $70 \%$ alcohol. A 2-cm midline incision was made using a scalpel, and the skull was exposed by using two cotton-tipped applicators to gently push the periosteum of the skull to the most lateral edges of the incision, applying gentle pressure to absorb bleeding and dry exposed skull. The scored side of the stainless steel disk $(10 \mathrm{~mm}$ in diameter and $3 \mathrm{~mm}$ in thickness) was coated with cyanoacrylic glue and mounted on the parietal bone midline between bregma and lambda, straddling the sagittal suture. After the glue dried for 5 minutes, the animal was placed prone on the foam bed, under the hollow Plexiglass tube, and was secured by strapping surgical tape over the dorsal surface attached to either side of the Plexiglas bed. Mild TBI was induced by dropping the cylindrical column of segmented brass $(450 \mathrm{~g})$ through the Plexiglas tube from a 1-m height onto the stainless steel disc fixed to the skull vault of the animal. Rebound impact was prevented simply by quickly sliding the Plexiglas box (foam bed) containing the animal away from the tube immediately following the initial impact. To prevent skull fractures, a small stainlesssteel helmet-disc was placed on the rodent skull while the animal was supported by the foam bed. The metal helmet was removed and incision closed with sterile 4-0 suture. Sham animals underwent identical anesthesia and surgery but did not receive impact injury.

\section{Experimental Groups and Treatment}

Thirty rats were divided into 3 groups: 1$) \mathrm{mTBI}+$ Cerebrolysin $(\mathrm{n}=11), 2) \mathrm{mTBI}+$ saline (vehicle, $\mathrm{n}=11$ ), and sham $(\mathrm{n}=8)$. Cerebrolysin or saline at $2.5 \mathrm{ml} / \mathrm{kg}$ was administered intraperitoneally once daily for 28 days, starting at 24 hours after injury, which was chosen based on our stroke study with Cerebrolysin in rats. ${ }^{103}$ The animals with mTBI treated using saline (vehicle) were used as a control group. Sham animals underwent surgery without injury and treatment. For labeling proliferating cells, 5'-bromo-2'-deoxyuridine (BrdU, $100 \mathrm{mg} / \mathrm{kg}$ ) was injected intraperitoneally into rats daily for 10 days, starting 1 day after mTBI. The dose and time for BrdU injection were based on our previous TBI studies in rats. ${ }^{65,100}$ All animals were allowed to survive 90 days after mTBI.

\section{Evaluation of Neurological Outcome}

\section{Morris Water Maze (MWM) Test}

All functional tests were performed by investigators blinded to the treatment status. To measure spatial learning impairments, an updated version of the MWM test was used..$^{10}$ The procedure was modified from previous versions ${ }^{70}$ and has been found to be useful for spatial memory assessment in rodents with brain injury. ${ }^{10}$ The MWM test was performed monthly postinjury. At each testing interval, animals were tested with 4 trials per day for 5 consecutive days on Days 30-34, 61-65, and 86-90 after mTBI. 
A blue swimming pool (1.8 $\mathrm{m}$ in diameter) was located in a large room, where there were many clues external to the maze (such as pictures on the walls, lamps, and a camera on the ceiling); these were visible from the pool and presumably used by the rats for spatial orientation. The position of the cues remained unchanged throughout the experiment. Data collection was automated using the HVS Image 2020 Plus Tracking System (US HVS Image), as described previously. ${ }^{58}$ For data collection, the swimming pool was subdivided into 4 equal quadrants formed by imaging lines. At the start of each trial, the rat was placed at 1 of 4 fixed starting points, randomly facing toward a wall (designated North, South, East, and West) and allowed to swim for 90 seconds or until it found the platform, which was transparent and invisible to the animals. If the animal found the platform by spatial navigation, it was allowed to remain on it for 10 seconds. If the animal failed to find the platform within 90 seconds, it was placed on the platform for 10 seconds. Throughout the test period, the platform was located in the northeast quadrant $2 \mathrm{~cm}$ below water in a randomly changing position, including locations against the wall, toward the middle of the pool, or offcenter, but always within the target quadrant. If the animal was unable to locate the platform within 90 seconds, the trial was terminated and a maximum score of 90 seconds was assigned. If the animal reached the platform within 90 seconds, the percentage of time traveled within the northeast (correct) quadrant was calculated relative to the total amount of time spent swimming before reaching the platform and employed for statistical analysis. The latency to find the hidden escape platform was also recorded and analyzed. The advantage of this version of the water maze is that each trial takes on the key characteristics of a probe trial because the platform is not in a fixed location within the target quadrant. In the traditional version of the MWM test, the position of the hidden platform is always fixed and is relatively easy for rodents to find. With the modified MWM test we used in this study, the platform is relocated randomly within the correct quadrant with each training trial. The rodents must spend more time searching within the target quadrant; therefore, each trial effectively acts as a probe trial. The advantage of this protocol is that rodents should find the platform purely and extensively by reference to the extramaze spatial cues, which improves the accuracy of spatial performance in the MWM. ${ }^{10}$

\section{Social Odor-Based Novelty Recognition Test}

The odor recognition test was performed in the home cage, as described previously, including a familiarization phase, an odor habituation phase, and an odor recognition memory test phase..$^{90}$ On arrival, experimental rats were individually housed in cages. Social odors were presented to the rats on wooden beads, each scented with the odor of a single conspecific animal. To obtain social odors from conspecifics, round wooden beads with a hole (BE1090, Woodworks Ltd.) were scented by being placed in the cage of an individually housed odor donor rat for 1 week without bedding change to allow for a buildup of animalspecific novel odors. ${ }^{77}$ During the initial 24-hour familiarization period (at 43 or 88 days after TBI), 4 unscented wooden beads (designated as F1-F4) were introduced into the home cage where a rat would be familiarized with both the testing environment and the presence of the beads for 24 hours. On the following day (that is, at 44 or 89 days after $\mathrm{mTBI}$ ), during the odor habituation phase of the task, the 4 now-familiar beads were removed for 1 hour. After this 1-hour period, 3 familiar beads (F1-F3) removed from their own cages 1 hour prior and a novel-odor wooden bead (N1), taken from an odor-donor cage to replace the F4 bead, were placed into the home cage. The animals were exposed to these 4 beads (F1-F3 and N1) for three 1-minute trials with 1-minute intertrial intervals, during which the beads were removed from the home cage. This procedure produces habituation to N1 while minimizing olfactory adaptation. For each 1-minute trial, the 3 familiar-odor beads (F1-F3) and the N1 bead were placed in the middle of the testing home cage, and the rats were allowed $1 \mathrm{~min}$ ute to actively explore the beads. The first approach to a bead made during this period initiated the timing of the 1-minute trial. Exploration time for each of the 4 beads was recorded by experimenters blinded to which beads were familiar or novel (beads were number-coded). The spatial arrangement of the beads in the middle of the cage was randomly altered between trials. To maximize the sensitivity of the test, 1 novel (N1) and 3 familiar-odor beads were used during habituation trials, rather than N1 only.

The odor-recognition memory test was then performed. At 45 or 90 days after injury, and 24 hours after the novel-odor habituation phase, the odor-recognition memory test was conducted. ${ }^{90}$ During odor recognition memory retention assessment, 4 beads were used ( 2 familiar home cage beads F1 and F2, recently familiar bead N1, and an unfamiliar novel-odor bead N2) rather than N1 and N2 only. The 4-choice procedure for assessing relative odor preference greatly increases power (sensitivity and reliability) compared with 2-choice procedures typically used in recognition memory tests. For this phase of the task, rats were presented with the odor N1 bead (which it had thoroughly explored on the previous day, that is, at 44 or 89 days postinjury) in the presence of 1 unfamiliar novel-odor N2 bead taken from a different odor-donor cage and 2 familiar (own-cage) odor beads, following the same procedure outlined for the habituation phase. To avoid a confounding effect of scent marking, the N1 bead was discarded after habituation and replaced by another N1 bead taken from the same odor-donor cage for the recognition memory phase. In this study, the focus was to assess overnight memory for the N1 bead. Good memory was indicated by significantly more time spent exploring N2 than $\mathrm{N} 1$ on the first trial of the odor-recognition memory test.

\section{Tissue Preparation}

Rats were anesthetized with chloral hydrate administered intraperitoneally and perfused transcardially with saline solution, followed by $4 \%$ paraformaldehyde in $0.1 \mathrm{M}$ phosphate-buffered saline (PBS), pH 7.4. Rat brains were removed and immersed in 4\% paraformaldehyde for 2-4 days. Using a rat brain matrix (Activational Systems Inc.), each forebrain was cut into 2-mm-thick coronal blocks for a total of 7 blocks from bregma $5.2 \mathrm{~mm}$ to bregma -8.8 $\mathrm{mm}$ per animal. ${ }^{78}$ The tissues were embedded in paraffin, and a series of $6-\mu \mathrm{m}$-thick slides were cut. 


\section{Immunohistochemical Analysis}

Antigen retrieval was performed by boiling brain sections in $10 \mathrm{mM}$ citrate buffer ( $\mathrm{pH}$ 6.0) for 10 minutes. After washing with PBS, sections were incubated with $0.3 \%$ $\mathrm{H}_{2} \mathrm{O}_{2}$ in PBS for 10 minutes, blocked with $1 \%$ bovine serum albumin (BSA) containing 0.3\% Triton-X 100 at room temperature for 1 hour, and incubated with mouse anti-doublecortin (1:200; DCX, Santa Cruz Biotechnology), rabbit polyclonal anti-glial fibrillary acidic protein (1:1000; GFAP, Dako), and monoclonal mouse anti-APP A4 (1:400; MAB348, Chemicon, Millipore) at $4^{\circ} \mathrm{C}$ overnight. For negative controls, primary antibodies were omitted. After washing, sections were incubated with biotinylated anti-mouse or anti-rabbit antibodies (1:200; Vector Laboratories, Inc.) at room temperature for $30 \mathrm{~min}$ utes. After an additional washing, sections were incubated with an avidin-biotin-peroxidase system (ABC kit; Vector Laboratories, Inc.), visualized with diaminobenzidine (Sigma), and counterstained with hematoxylin.

\section{Immunofluorescent Staining}

Newly generated mature neurons in the dentate gyrus were identified by double labeling for BrdU and neuronal nuclei (NeuN) 90 days after mTBI. ${ }^{100}$ Briefly, after being deparaffinized and rehydrated, brain sections were boiled in $10 \mathrm{mM}$ of citric acid buffer (pH 6) for 10 minutes. After washing with PBS, sections were incubated in $2.4 \mathrm{~N}$ $\mathrm{HCl}$ at $37^{\circ} \mathrm{C}$ for 20 minutes. Sections were incubated with $1 \%$ BSA containing $0.3 \%$ Triton-X-100 in PBS. Sections were then incubated with mouse anti-NeuN antibody (1:200; Chemicon) at $4^{\circ} \mathrm{C}$ overnight. For negative controls, primary antibodies were omitted. Fluorescein isothiocyanate-conjugated anti-mouse antibody (1:400; Jackson ImmunoResearch) was added to sections at room temperature for 2 hours. Sections were then incubated with rat antiBrdU antibody (1:200; Dako) at $4^{\circ} \mathrm{C}$ overnight. Sections were then incubated with $\mathrm{Cy} 3$-conjugated goat anti-rat antibody (1:400; Jackson ImmunoResearch) at room temperature for 2 hours. Each of the steps was followed by three 5 -minute rinses in PBS. Tissue sections were mounted with Vectashield mounting medium (Vector laboratories).

\section{Cell Counting and Quantitation}

Doublecortin-positive cells were examined within the granule cell layer and subgranular zone of the dentate gyrus of the hippocampus. GFAP-positive cells and APPpositive areas were examined in the cortex, corpus callosum, dentate gyrus, CA1, and CA 3 regions. For analysis of neurogenesis, we focused on the dentate gyrus and its subregions, including the subgranular zone, granular cell layer, and molecular layer. The number of BrdU-positive cells (red-stained) and NeuN/BrdU-colabeled cells (yellow after merge) were counted in the dentate gyrus. The fields of interest were digitized under the light microscope (Nikon, Eclipse 80i) at a magnification of either 200 or 400 using CoolSNAP color camera (Photometrics) interfaced with MetaMorph image analysis system (Molecular Devices), as previously described in detail. ${ }^{105}$ The immunopositive cells or area of positive staining was calculated and divided by the measured areas, and presented as numbers per square millimeter or percentage of area. Cell counting and area measurements were performed by observers blinded to the individual treatment status of the animals. All counting was performed on a computer monitor to improve visualization and in 1 focal plane to avoid oversampling. ${ }^{104}$

\section{Statistical Analysis}

Data are presented as means with standard deviations. ANOVA was used for repeated measurements of spatial performance. For cell counting, percentage of positive area, and odor test, a 1-way ANOVA followed by post hoc Tukey tests were used to compare the differences between the Cerebrolysin-treated, saline-treated, and sham groups. Pearson correlation coefficients were calculated to examine relationships between cognitive functional recovery and immunostaining. Statistical significance was set at $\mathrm{p}$ $<0.05$.

\section{Results \\ Mild TBI Model}

In this study, the well-characterized Marmarou impact acceleration model was employed, which mimics the most common type of TBI observed clinically. ${ }^{35,62,73}$ It is well documented that a fall of a 450-g brass weight from a height of 1 meter through a Plexiglas guide tube onto a protective stainless disc fixed to the skull of adult rats weighing 350-400 g causes an mTBI both histopathologically and biochemically. ${ }^{21,62,86}$ In the present study, the impact induced by $450 \mathrm{~g} \times 1 \mathrm{~m}$ did not result in acute or delayed death. All animals recovered righting reflexes in approximately 2 minutes following sham surgery or impact. No skull fracture or death occurred when $450 \mathrm{~g} \times 1$ $\mathrm{m}$ impact was applied to the protective metal disc glued to the intact skull in our present study, which is in agreement with the report by others..$^{21}$ There was no significant difference in body weight among 3 groups over the 90-day study. No focal lesions, hematomas, or apparent cell loss were observed in the brain, including the cortex and the hippocampus, under the impact site in $\mathrm{H} \& \mathrm{E}$-stained brain sections (data not shown). These observations indicate that the impact of $450 \mathrm{~g} \times 1 \mathrm{~m}$ induced $\mathrm{mTBI}$ in this study.

\section{Cerebrolysin Administration and Spatial Learning}

We used the modified MWM test to evaluate spatial learning impairment. The more time a rat spends in the correct quadrant, the better the spatial learning function. In testing of spatial memory at 1 month (Fig. 1A), no significant between-group effect on the time spent in the correct quadrant was detected on the first day of the testing in the MWM test (Day 30 postinjury, $\mathrm{F}_{2,27}=0.28, \mathrm{p}=$ 0.746 ); however, a statistically significant between-group effect on the time spent in the correct quadrant was noted on the MWM test on Days $31\left(\mathrm{~F}_{2,27}=22.06, \mathrm{p}<0.001\right)$, $32\left(\mathrm{~F}_{2.27}=27.96, \mathrm{p}<0.001\right), 33\left(\mathrm{~F}_{2,27}=38.60, \mathrm{p}<0.001\right)$, and $34\left(\mathrm{~F}_{2,27}=30.43, \mathrm{p}<0.001\right)$. Relative to the saline group, post hoc Tukey testing demonstrated significantly increased time spent in the correct quadrant in the Cerebrolysin group at Days 31-34 (p < 0.001). At 2 months after injury (Fig. 1B), a statistically significant between- 
A 1 month

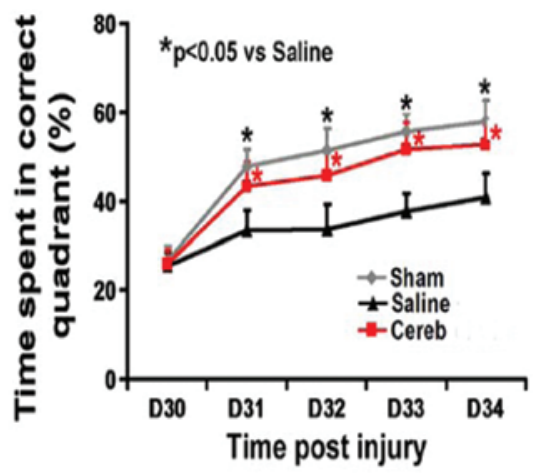

D

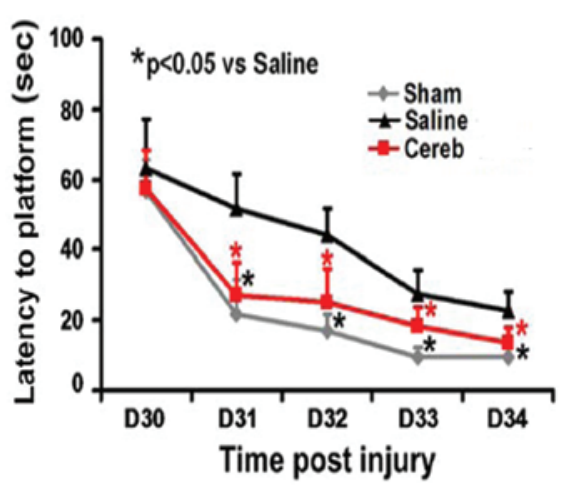

B 2 months

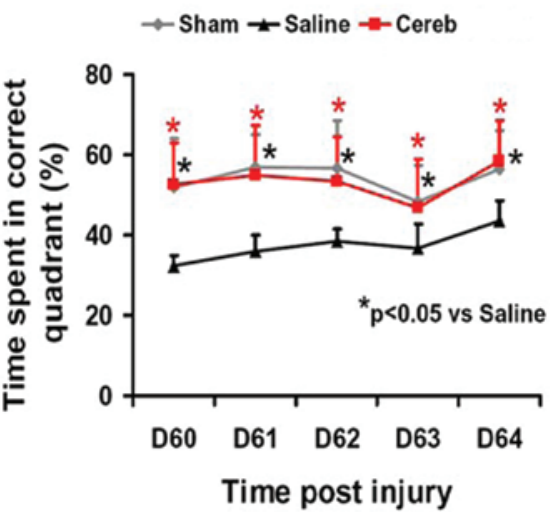

E

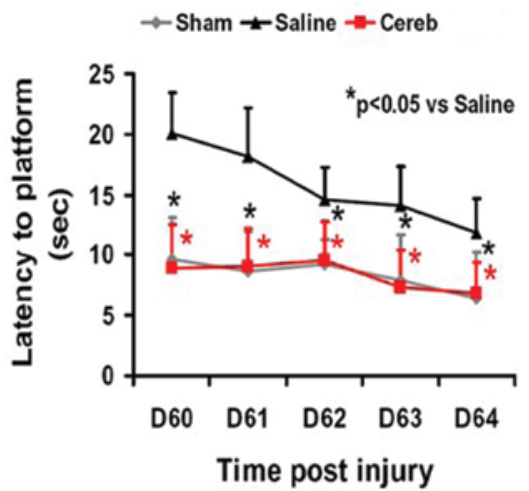

C 3 months

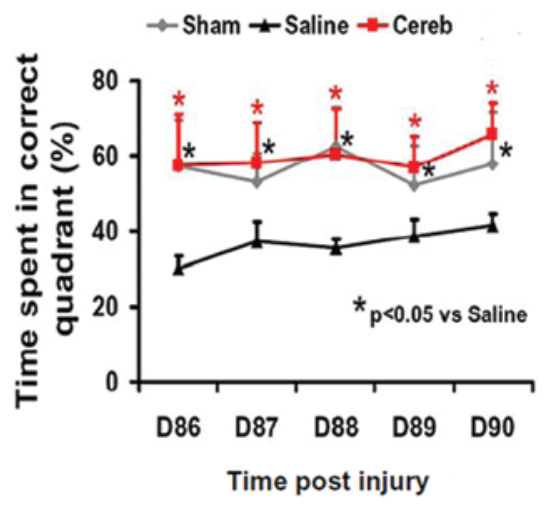

$\mathbf{F}$

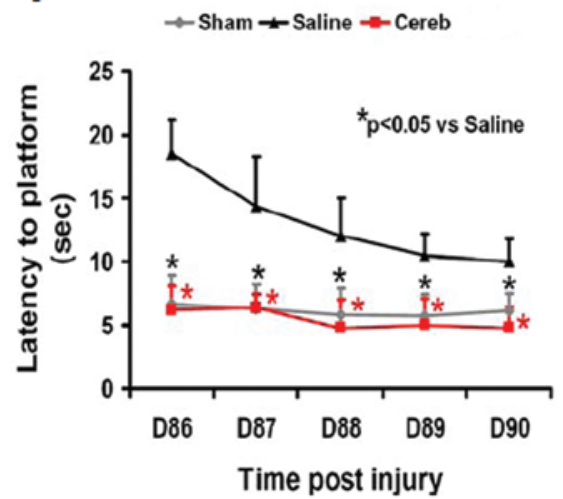

FIG. 1. Graphs of the effects of Cerebrolysin (Cereb) on spatial learning performance. A-C: Cerebrolysin treatment significantly improved spatial learning performance compared with the saline group at 1, 2, and 3 months after mTBI. D-F: Cerebrolysin treatment significantly reduced the time to reach the hidden platform in the MWM compared with the saline group at 1, 2, and 3 months after mTBI. Data represent mean \pm SD. There were 8-11 rats per group. Figure is available in color online only.

group effect on the time spent in the correct quadrant was noted in the MWM test on Days $60\left(\mathrm{~F}_{2,27}=16.76, \mathrm{p}<\right.$ $0.001), 61\left(\mathrm{~F}_{2,27}=16.98, \mathrm{p}<0.001\right), 62\left(\mathrm{~F}_{2,27}=11.14, \mathrm{p}<\right.$ $0.001), 63\left(\mathrm{~F}_{2,27}=5.13, \mathrm{p}=0.013\right)$, and $64\left(\mathrm{~F}_{2,27}=9.66, \mathrm{p}<\right.$ $0.001)$. Post hoc Tukey testing demonstrated significantly increased time spent in the correct quadrant in the Cerebrolysin group on Days 60-64 compared to the saline group (p < 0.001). At 3 months after injury (Fig. 1C), a statistically significant between-group effect on the time spent in the correct quadrant was noted in the MWM test on Days $86\left(\mathrm{~F}_{2,27}=32.68, \mathrm{p}<0.001\right), 87\left(\mathrm{~F}_{2,27}=19.62, \mathrm{p}\right.$ $<0.001), 88\left(\mathrm{~F}_{2,27}=27.79, \mathrm{p}<0.001\right), 89\left(\mathrm{~F}_{2,27}=15.68, \mathrm{p}\right.$ $<0.001)$, and $90\left(\mathrm{~F}_{2,27}=20.92, \mathrm{p}<0.001\right)$. Post hoc Tukey testing demonstrated significantly increased time spent in the correct quadrant in the Cerebrolysin group at Days 86-90 compared with the saline group ( $p<0.01)$.

Another important parameter for assessing spatial learning in the MWM test is the latency for animals to find the hidden platform in the correct quadrant. ${ }^{105}$ The less time it takes for animals to find the platform, the better the spatial learning function. At 1 month after injury (Fig. 1D), no significant between-group effect on the time for animals to find the hidden platform in the correct quadrant was detected in the MWM test on Day $30\left(\mathrm{~F}_{2,27}=0.90, \mathrm{p}=0.418\right)$; however, a statistically significant between-group effect on the latency to find the hidden platform in the correct quadrant was noted in the MWM test on Days $31\left(\mathrm{~F}_{2,27}=26.32\right)$, $32\left(\mathrm{~F}_{2,27}=31.33\right), 33\left(\mathrm{~F}_{2,27}=23.29\right)$, and $34\left(\mathrm{~F}_{2,27}=19.26 ; \mathrm{p}\right.$ $<0.001$ for Days 31-34). Relative to the saline group, post hoc Tukey testing demonstrated significantly less time for animals to find the platform in the Cerebrolysin group during the last 4 days of testing (Days 31-34; $p<0.001$ ). At 2 months after injury (Fig. 1E), a statistically significant between-group effect on the latency to find the hidden platform in the correct quadrant was noted in the MWM test on Days $60\left(\mathrm{~F}_{2,27}=33.42\right), 61\left(\mathrm{~F}_{2,27}=23.48\right), 62\left(\mathrm{~F}_{2,27}=13.01\right)$, $63\left(\mathrm{~F}_{2.27}=17.43\right)$, and $64\left(\mathrm{~F}_{2,27}=21.79 ; \mathrm{p}<0.001\right.$ for Days $60-64)$. Relative to the saline group, post hoc Tukey testing demonstrated significantly less time for animals to find the platform in the Cerebrolysin group on Days 60-64 ( $p<$ 0.001 ). At 3 months after injury (Fig. 1F), a statistically significant between-group effect on the latency for animals to find the hidden platform in the correct quadrant was noted in the MWM test on Days $86\left(\mathrm{~F}_{2,27}=94.63\right), 87\left(\mathrm{~F}_{2,27}=\right.$ 32.06), $88\left(\mathrm{~F}_{2.27}=21.44\right), 89\left(\mathrm{~F}_{2,27}=27.99\right)$, and $90\left(\mathrm{~F}_{2,27}\right.$ $=39.30 ; \mathrm{p}<0.001$ for Days 86-90). Relative to the saline group, post hoc Tukey testing demonstrated significantly less time for animals to find the platform in the Cerebrolysin group on Days 86-90 ( $\mathrm{p}<0.001)$. These results indicate that the beneficial effects of Cerebrolysin-administered 
starting 24 hours after injury for 28 days-on spatial learning cognition last for at least 3 months in rats after mTBI.

\section{Cerebrolysin Treatment and Nonspatial Social Odor-Based Recognition}

The social odor-based recognition task was performed to detect nonspatial memory deficits after mTBI. The saline-treated mTBI rats failed to form new memories after mTBI, which caused anterograde amnesia, leading to an inability to recall the recent past odor bead (N1) after a 24-hour delay tested on Days 45 (Fig. 2A) and 90 (Fig. 2B) after mTBI. Compared with the saline group, both sham rats and Cerebrolysin-treated mTBI rats spent significantly more time exploring the novel odor bead (N2) than the N1 bead, showing a strong preference for the N2 bead over the N1 bead on Day $45\left(\mathrm{~F}_{2,27}=39.69, \mathrm{p}<0.001\right)$ and Day $90\left(\mathrm{~F}_{2,27}=71.07, \mathrm{p}<0.001\right)$ after mTBI. However, salinetreated mTBI rats spent almost an equal time exploring both $\mathrm{N} 1$ and N2 beads, showing severe memory deficit on Day $45\left(\mathrm{~F}_{2,27}=0.79, \mathrm{p}=0.466\right)$ and Day $90\left(\mathrm{~F}_{2,27}=0.01\right.$, $\mathrm{p}=0.999)$ after mTBI. These data indicate that nonspatial social odor-based memory impairment occurred up to 3 months after mTBI and that Cerebrolysin treatment starting 24 hours after injury for 28 days had a long-lasting therapeutic effect on this nonspatial cognition.

\section{Cerebrolysin Treatment and the Number of Neuroblasts and Newborn Mature Neurons in the Dentate Gyrus}

Doublecortin is an endogenous marker of neuroblasts. Neural stem/progenitor cells residing in the subgranular zone of the dentate gyrus generate new neurons throughout life, ${ }^{45}$ and after TBI. ${ }^{7}$ A statistically significant betweengroup effect on the number of DCX-positive cells was noted (Fig. 3; $\mathrm{F}_{2,27}=24.74, \mathrm{p}<0.001$ ). Post hoc Tukey testing demonstrated that mTBI significantly decreased the number of DCX-positive neuroblasts in the saline group compared with the sham group (Fig. 3A and B, p < 0.001). However, treatment with Cerebrolysin significantly increased the number of neuroblasts in the subgranular zone com- pared with the saline group (Fig. 3B-D, p < 0.001). Double immunostaining for BrdU (proliferating cell marker) and NeuN (mature neuronal marker) was performed to identify newly generated mature neurons in the dentate gyrus. A statistically significant between-group effect on the number of BrdU/NeuN-positive cells was noted (Fig. 3; $\mathrm{F}_{2,27}=$ 29.91, $\mathrm{p}<0.001)$. Post hoc Tukey testing demonstrated that mTBI decreased the number of newborn mature neurons in the dentate gyrus compared with sham controls (Fig. 3E and F; $\mathrm{p}<0.001)$. However, Cerebrolysin treatment significantly increased the number of newborn mature neurons in the dentate gyrus compared with vehicle controls (Fig. $3 \mathrm{~F}-\mathrm{H} ; \mathrm{p}<0.001)$. Pearson correlation coefficients were calculated to determine whether a relationship exists between the cognitive functional outcome and the number of neuroblasts and newborn mature neurons in the dentate gyrus. Our data further show that spatial learning was positively correlated with the number of DCX-positive neuroblasts $(\mathrm{r}=0.6891, \mathrm{p}<0.001)$ and with the number of newborn mature neurons $(r=0.7393, p<0.001)$ in the dentate gyrus examined at Day 90 after mTBI. Odor recognition memory was also positively correlated with the number of DCXpositive neuroblasts $(\mathrm{r}=0.7128, \mathrm{p}<0.001)$ and with the number of newborn mature neurons $(\mathrm{r}=0.7158, \mathrm{p}<0.001)$ examined at Day 90 after mTBI.

\section{Cerebrolysin Treatment and Brain APP Accumulation}

APP staining is a universally accepted marker for detecting traumatic axonal injury in all severities of TBI including mTBI. ${ }^{33,63}$ A statistically significant betweengroup effect on the APP accumulation was detected in the corpus callosum $\left(\mathrm{F}_{2,27}=209.87, \mathrm{p}<0.001\right)$, cortex $\left(\mathrm{F}_{2,27}\right.$ $=510.87, \mathrm{p}<0.001)$, dentate gyrus $\left(\mathrm{F}_{2,27}=300.01, \mathrm{p}<\right.$ $0.001), \mathrm{CA} 1\left(\mathrm{~F}_{2,27}=647.17, \mathrm{p}<0.001\right)$, and CA3 $\left(\mathrm{F}_{2,27}=\right.$ $304.18, \mathrm{p}<0.001)$ regions. Post hoc Tukey testing demonstrated that significant APP accumulation was observed in the corpus callosum, cortex, dentate gyrus, CA1, and CA3 regions in saline-treated rats when examined at 3 months after mTBI compared with sham controls (Fig. 4A-N, p <
A Day 45 post injury

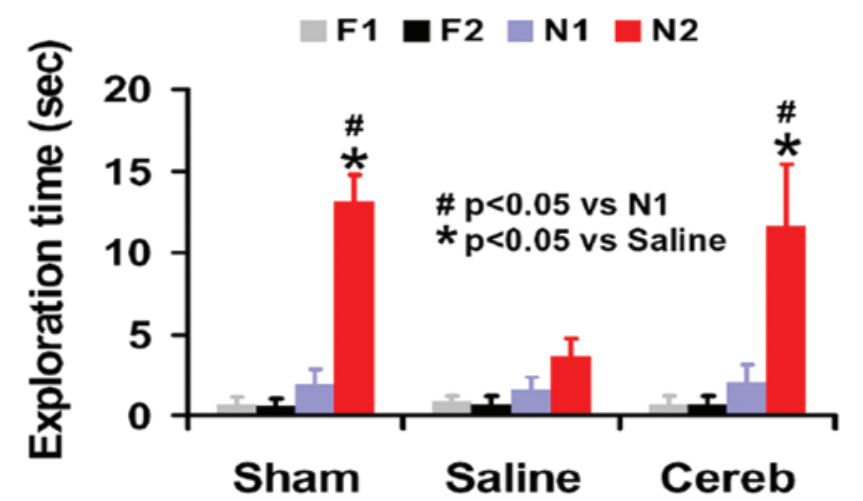

\section{B Day 90 post injury}

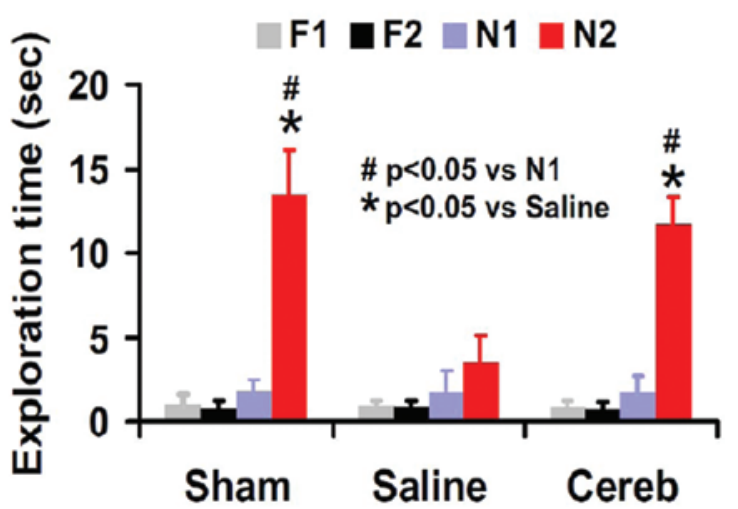

FIG. 2. Graphs of the effects of Cerebrolysin (Cereb) on nonspatial social odor-based novelty recognition memory. Sham rats spend significantly more time exploring the novel odor bead (N2) than the N1 familiar bead. Cerebrolysin treatment significantly improves nonspatial social odor-based novelty recognition memory compared with the saline group at 45 (A) and 90 (B) days after mTBI. F1 and F2 = familiar home-cage beads; N1 = familiar odor bead; N2 = unfamiliar novel odor bead. Data represent mean $\pm \mathrm{SD}$. There were $8-11$ rats per group. Figure is available in color online only. 

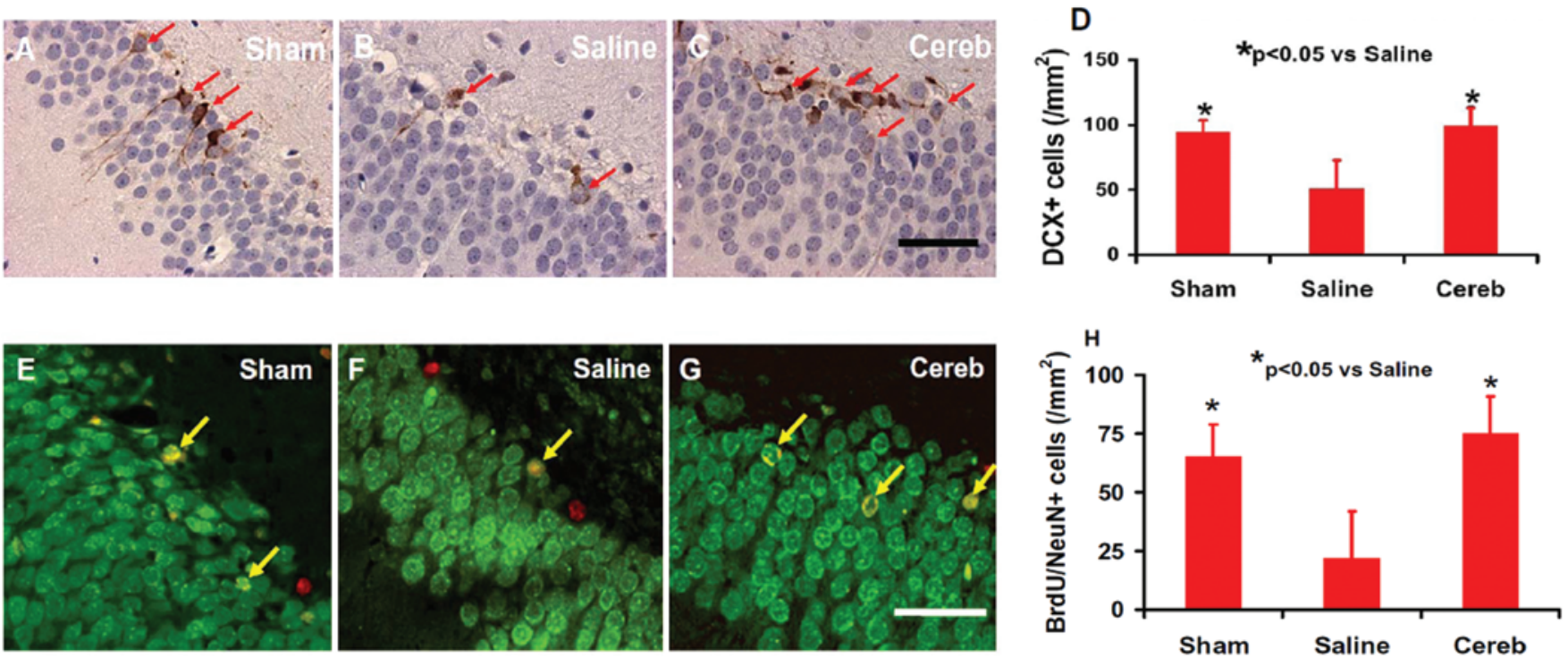

FIG. 3. The effects of Cerebrolysin (Cereb) on the number of DCX-expressing neuroblasts and BrdU/NeuN-positive newborn mature neurons in the dentate gyrus. DCX staining was used to identify neuroblasts in the dentate gyrus, as indicated by red arrows (A-C). Compared with the saline-treated group (B), Cerebrolysin treatment (C) significantly increased DCX-positive neuroblasts in the dentate gyrus 90 days after mTBI, which is comparable to the sham level (A). The bar graph (D) shows the number of DCX-positive neuroblasts. Compared with the saline-treated group (F), Cerebrolysin treatment (G) significantly increased newborn mature neurons identified with BrdU/NeuN double immunofluorescent staining in the dentate gyrus as indicated by yellow arrows, at 90 days postinjury. The bar graph $(\mathrm{H})$ shows the number of BrdU/NeuN-positive newborn mature neurons. Scale bar $=50 \mu \mathrm{m}$. Data in the graphs represent mean \pm SD. There were 8-11 rats per group. Figure is available in color online only.

0.001). Cerebrolysin treatment significantly reduced APP accumulation in these regions as compared with salinetreatment (Fig. 4B-P, p < 0.001, Tukey post hoc test). The Pearson correlation analyses show that spatial learning was negatively correlated with APP levels in all the brain regions examined at Day 90 after mTBI (with $\mathrm{r}$ values in the range of -0.8417 to $-0.8940, p<0.001$ for all brain regions). Odor recognition memory was also negatively correlated with APP levels in all the brain regions examined on Day 90 after mTBI (with $r$ values in the range of -0.7605 to $-0.9178, \mathrm{p}<0.001$ for all brain regions).

\section{Cerebrolysin Treatment and Astrocyte Activation}

We performed immunohistochemical staining of GFAP for the detection of reactive astrocytes. A statistically significant between-group effect on GFAP activation was detected in the corpus callosum $\left(\mathrm{F}_{2,27}=4.49, \mathrm{p}=0.021\right)$, cortex $\left(\mathrm{F}_{2,27}=19.18, \mathrm{p}<0.001\right)$, dentate gyrus $\left(\mathrm{F}_{2,27}=10.12, \mathrm{p}\right.$ $<0.001)$, CA1 $\left(\mathrm{F}_{2,27}=9.5, \mathrm{p}<0.001\right)$, and CA3 $\left(\mathrm{F}_{2,27}=6.23\right.$, $\mathrm{p}=0.006)$ regions. Post hoc Tukey testing demonstrated that diffuse astrocyte activation was observed in various brain regions including the corpus callosum, cortex, CA1, CA3, and dentate gyrus on Day 90 after mTBI compared with the sham group (Fig. 5A-N, p < 0.001). Cerebrolysin inhibited astrocyte activation in these brain regions in rats after mTBI compared with the saline group (Fig. 5B-P, p < $0.001)$. The Pearson correlation analyses further show that spatial learning was negatively correlated with the number of GFAP-positive cells in all the brain regions examined at Day 90 after mTBI (with $r$ values in the range of -0.5492 to $-0.7895, p<0.001$ for all brain regions). Odor recognition memory was also negatively correlated with the number of GFAP-positive cells in all the brain regions examined at
Day 90 after mTBI (with $r$ values in the range of -0.5008 to $-0.6470, p<0.001$ for all brain regions).

\section{Discussion}

The primary findings in the present study are as follows: 1) mTBI produces long-lasting spatial and nonspatial cognitive impairments persisting for at least 3 months; 2) treatment of mTBI with Cerebrolysin initiated 24 hours postinjury improves cognitive functional outcomes; and 3) Cerebrolysin treatment significantly increases the number of DCX-expressing neuroblasts and BrdU/NeuN-positive mature neurons in the dentate gyrus and significantly reduces brain APP accumulation and astrocyte activation.

Mild TBI is a poorly understood health problem and can result in short- and long-term cognitive, behavioral, and emotional impairments. ${ }^{67,101,109}$ Mild TBI is not typically associated with gross brain damage. However, persistent inflammation may persist for many years after just a single TBI in humans. ${ }^{32}$ Inflammatory reactive astrocytosis occurs prominently in response to all forms of neural injury or disease ${ }^{88}$ Both beneficial and detrimental effects have been attributed to reactive astrocytes after TBI. ${ }^{47,72}$ Several studies have demonstrated that posttraumatic antiinflammatory treatments are able to modulate neuroinflammation and reduce cognitive impairment from several days to 3 months in animal models of mTBI. ${ }^{23,24,53} \mathrm{~A}$ previous study indicated that mTBI mainly activates inflammatory processes including astrocyte activation in a mouse weight-drop, closed-head injury model.$^{30}$ In the present study, our data indicate that Cerebrolysin improves cognitive function, with a significant negative correlation with astrocyte activation, suggesting that astrocyte activation 


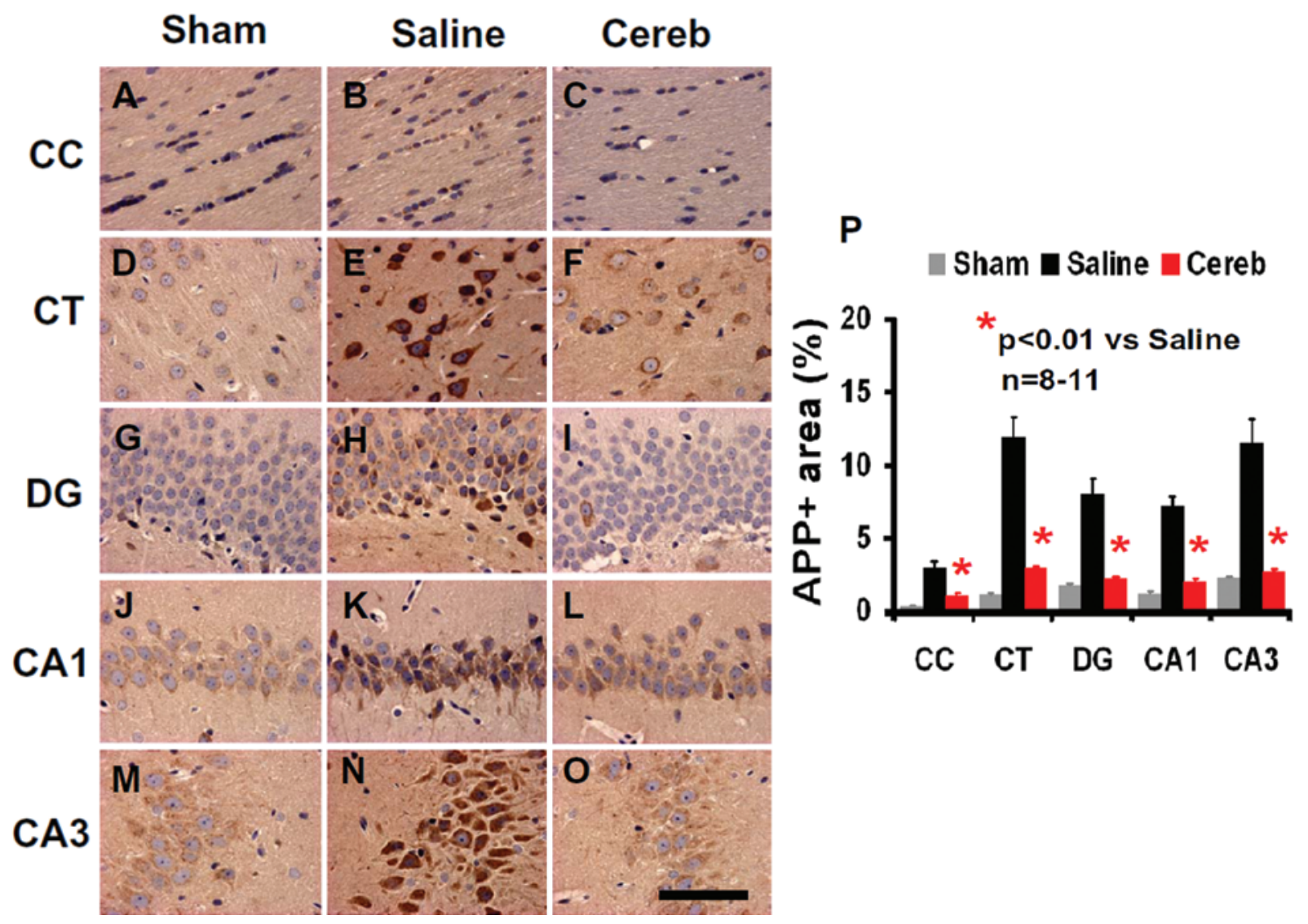

FIG. 4. The effects of Cerebrolysin (Cereb) on brain APP accumulation. APP is weakly expressed in brain regions of sham animals (A, D, G, J, and M). Compared with the saline-treated group (B, E, H, K, and N), Cerebrolysin treatment (C, F, I, L, and O) significantly reduces APP accumulation in various brain regions 90 days after mTBI. The data on APP-positive areas are shown in the bar graph $(P)$. CC = corpus callosum; $C T=$ cortex; $D G=$ dentate gyrus. Bar $=50 \mu \mathrm{m}$. Data in the graph represent mean $\pm S D$. There were 8-11 rats per group. Figure is available in color online only.

may play an important role in long-term cognitive impairments in rats after mTBI.

APP accumulation occurs rapidly and persists after TBI in both humans and animals. ${ }^{29,31,34,61}$ A recent study using APP knockout mice demonstrates that endogenous APP is beneficial after mTBI and that this neuroprotective activity is related to the soluble $\alpha$ form of APP (sAPP $\alpha) .{ }^{13} \mathrm{Un}-$ der normal conditions, most of the APP is processed along the nonamyloidogenic pathway leading to the formation of sAPP $\alpha$, which promotes neuroprotection, synaptic plasticity, neurite outgrowth, and synaptogenesis. ${ }^{43}$ Reduction of APP processing may lead to APP accumulation in the brain. A previous 7-day survival study shows that transient cognitive deficits and reversible APP accumulation occur after mTBI in gerbils. ${ }^{52}$ It is unknown whether these cognitive deficits and APP accumulation will reappear months after injury. In this study we show that cognitive impairment lasts up to 3 months after mTBI, which is concomitant with increased APP accumulation in many brain regions, including the hippocampus, cortex, and corpus callosum. Treatment with Cerebrolysin starting 24 hours after injury reduced the APP accumulation and reduced cognitive deficits in rats at 3 months after mTBI. This finding is consistent with a study in a transgenic Alzheimer's disease model, which demonstrated that Cerebrolysin attenuates cognitive deficits ${ }^{81}$ and reduces APP accumulation by regulating APP maturation. In addition, our data analyses show that there is a significant negative correlation between brain APP accumulation and cognitive function. Our results indicate that chronic APP accumulation is likely associated with long-term cognitive impairment in rats after mTBI. Further investigation of whether Cerebrolysin promotes APP processing toward sAPP $\alpha$ is warranted.

The MWM test is widely used for rodent cognition. It tests acquisition of spatial navigation and is sensitive to hippocampal injury. ${ }^{25,87}$ Way-finding cognition is impaired in humans after TBI, which is tested in a virtual arena maze simulating the MWM. ${ }^{54}$ Our present data indicate that closed-head mTBI causes spatial learning and memory impairment up to 3 months in rats measured by a new version of the MWM test. Our previous study demonstrated that persistent spatial learning deficits exist after mTBI induced by contusion and these deficits appear equivalent to deficits exhibited after a more severe injury in rats. ${ }^{16} \mathrm{~A}$ recent study shows that mice, even with a single closedhead mTBI, had a progressive decline in escape latency performance compared with sham controls during the acquisition testing from 6 to 18 months in the Barnes maze test, although mice with repeated mTBIs performed much worse compared with mice with a single mTBI. ${ }^{71}$ Increas- 


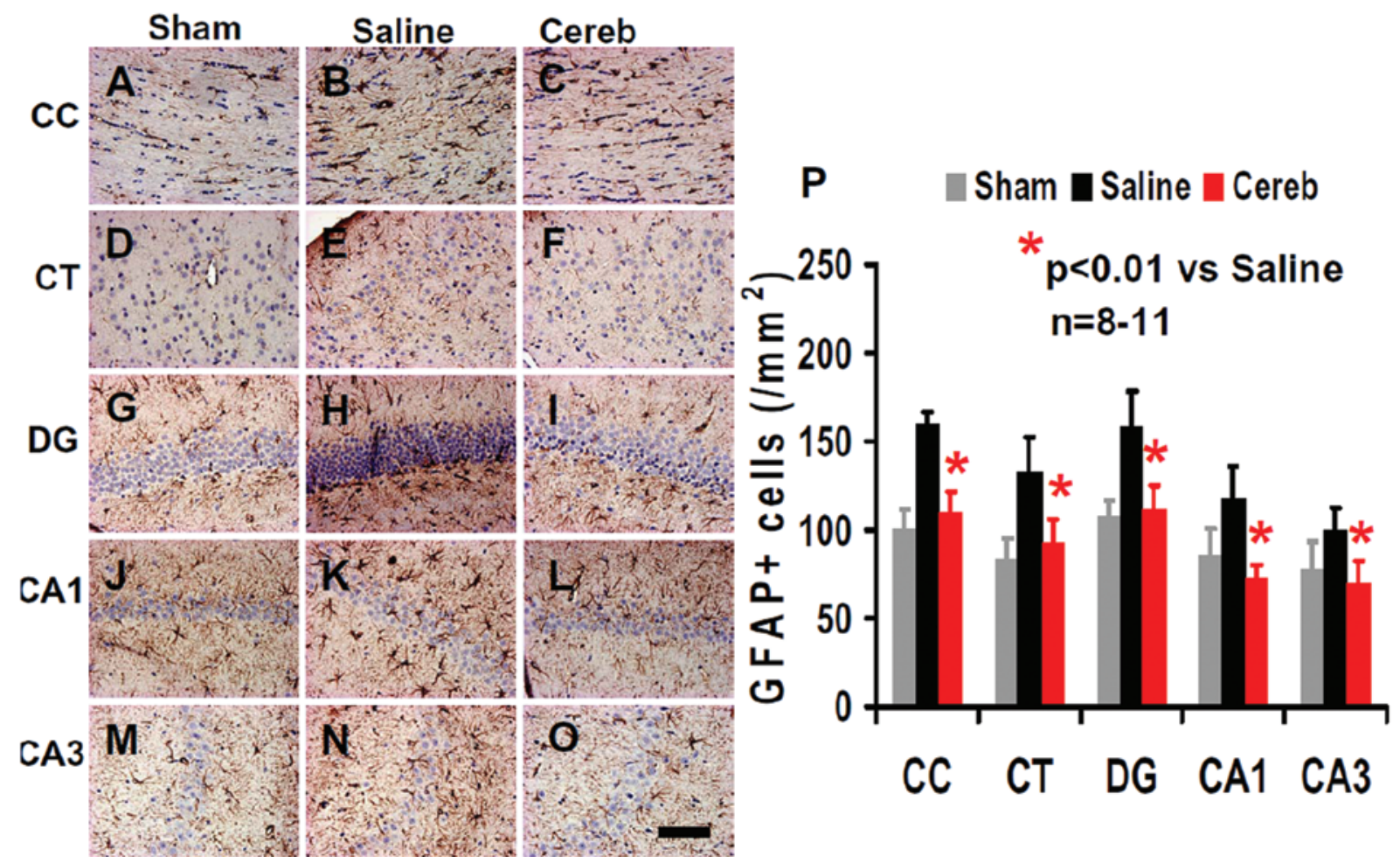

FIG. 5. The effects of Cerebrolysin (Cereb) on astrocyte activation. GFAP staining was performed to detect activation of astrocytes 90 days after mTBI. Some expression of GFAP was observed in brain regions of sham animals (A, D, G, J, and M). Cerebrolysin treatment (C, F, I, L, and O) significantly decreased GFAP-positive cells in various brain regions 90 days after mTBI compared with the saline group where prominent astrogliosis exists $(\mathrm{B}, \mathrm{E}, \mathrm{H}, \mathrm{K}$, and $\mathrm{N})$. $\mathrm{CC}=$ corpus callosum; $\mathrm{CT}=$ cortex; $\mathrm{DG}=$ dentate gyrus. The data on GFAP-positive cells are shown in the bar graph $(\mathbf{P})$. Bar $=50 \mu \mathrm{m}$. Data in graph represent mean \pm SD. Figure is available in color online only.

ing evidence from animal studies demonstrates that closedhead mTBI usually does not produce obvious structural damage to the brain and its surrounding tissue, but causes profound and long-lasting learning and memory impairments that are evident even 90 days postinjury. ${ }^{30,67,83,93,109,110}$ A recent clinical study shows that a cognitive deficit can be observed in patients with mTBI even 1 year after injury. ${ }^{17}$ The mechanisms underlying long-term cognitive impairment after mTBI are poorly understood.

Hippocampal integrity is critical for spatial learning and memory ${ }^{95}$ Generation of newborn neurons in the hippocampus is involved in spatial learning and memory in normal rats. ${ }^{59}$ Cerebrolysin has been shown to increase neurogenesis in models of stroke and Alzheimer's disease and improves functional outcomes. ${ }^{6,80,103}$ In the present study, mTBI decreased the number of DCX-expressing neuroblasts in the dentate gyrus, which may result in spatial learning impairment in rats after mTBI. A study using a knock-in mouse model that specifically ablates DCX-expressing neuroblasts in the dentate gyrus at an immature stage provides direct evidence that DCX-expressing neuroblasts are required for successful acquisition of spatial learning as well as reversal learning, but not for remembering.$^{98}$ In the present study, Cerebrolysin significantly enhanced the number of neuroblasts, which may be associated with improved spatial learning. In addition, continuous generation of new neurons from neural stem/progenitor cells in the subgranular zone of the den- tate gyrus is essential for hippocampal-dependent learning and memory ${ }^{107}$ Preclinical data from our group and others have shown that a large proportion of newly generated cells in the dentate gyrus die within 1 month in rodents after TBI ${ }^{56,92}$ In the present study, Cerebrolysin treatment increased the number of newborn mature neurons (BrdU/ NeuN-positive cells) in the dentate gyrus examined at 90 days after mTBI compared with saline controls. Furthermore, the Pearson correlation data showed a significant positive correlation between cognitive function and the number of DCX-positive neuroblasts and newborn mature neurons at Day 90 after mTBI. These data suggest that Cerebrolysin treatment stimulates and supports adult neurogenesis in the hippocampus, which may contribute to improvement in cognitive functional recovery after mTBI.

Substantial data have accumulated over the past two decades indicating that the adult brain is capable of widespread molecular, cellular, and anatomical changes and substantial functional reorganization mediating physical and mental experience and recovery from brain injury and in response to therapeutic treatment. ${ }^{11,12,14,38,41,76,106}$ In the present study we focused on hippocampal neurogenesis, which could sustain learning and memory through cellular organization. ${ }^{42}$ Recent findings support the premise that the hippocampus plays a major role in both spatial and nonspatial learning in humans with hippocampal damage. ${ }^{26,46}$ However, many other brain regions including the striatum, basal forebrain, cerebellum, and several neo- 
cortical areas are also involved in spatial navigation. ${ }^{19} \mathrm{We}$ cannot exclude the possibility that other brain regions also participate in functional recovery.

In the present study, there are several limitations. First, we have demonstrated that Cerebrolysin treatment significantly increased neurogenesis at 3 months after mTBI; however, measurements of the time course of the effect of Cerebrolysin on neurogenesis have not been conducted. Further investigations of Cerebrolysin on cell proliferation and differentiation are warranted and will be achieved by injecting BrdU at different time points after mTBI. The sequence of events of neurogenesis and the maturation of adult-born neurons have been established in rodents, and adult-born dentate granule neurons can functionally integrate into the existing hippocampal circuitry. ${ }^{68,107}$ Our data demonstrate a strong correlation between increased neurogenesis and cognitive functional recovery after mTBI and Cerebrolysin treatment. Newborn neurons generated from neural stem/progenitor cells in the subgranular zone of the dentate gyrus migrate into the granule cell layer and become functionally integrated into existing hippocampal circuits by the time new neurons are approximately 4 weeks of age. ${ }^{36,37,40,60}$ In our present study, almost all new mature neurons were detected in the granule cell layer at Day 90 after mTBI in the Cerebrolsyin-treated animals (Fig. 3G), suggesting that these new neurons may contribute to cognitive recovery. Confirmation of the functional integration of new hippocampal neurons is warranted and will be achieved by electrophysiological assessment and by measuring the branching patterns of newly generated neurons. It should also be noted that while dendritic maturation of new neurons in adult rodents requires about 4 weeks, ${ }^{40}$ maturation of new neurons in the adult monkey requires at least 5 weeks, ${ }^{75}$ and the time for maturation may exceed 6 months in the adult macaque monkey. ${ }^{44}$ There is substantial neurogenesis throughout life in the human hippocampus, and only a modest decline in neurogenesis occurs during aging. ${ }^{20,89}$ Although adult neurogenesis occurs in all mammals studied, substantial differences exist among mammals, including the time course of maturation of newborn neurons. Therefore, from a broader perspective, the time course of neurogenesis in human brains and their response to brain injury and therapeutic approaches may differ from rodents. We cannot simply extrapolate the experimental results from adult rodents to adult human brains, especially when translating the therapeutic treatments demonstrated to be effective in rodents to the clinical setting. Cerebrolysin's benefits could be attributed to many other mechanisms including synaptogenesis, oligodendrogenesis, and axonal and dendritic remodeling, which were not investigated in this study. As a caveat, in this study, we only sacrificed animals at 3 months after mTBI and measured APP, DCX, and GFAP at this time point. To obtain their dynamic profiling, measurements at multiple time points are warranted. Although several strong correlations between cognitive function and immunohistochemical analyses were found in this study, the cause-effect remains unknown. Further investigation of potential signaling pathways involved in the beneficial therapeutic effects of Cerebrolysin after mTBI is also warranted. Although Cerebrolysin is able to improve relatively long-term (3-month) cognitive function after mTBI in animals and humans, it is unclear how long the effects of Cerebrolysin treatment will last and whether and when cognitive and neuropathological alterations will reappear after treatment termination. Therefore, a longterm (i.e., 6-12 month) study on the effects of Cerebrolysin treatment in this clinically relevant animal model of mTBI is warranted.

Recognition memory refers to the process that allows both humans and animals to distinguish familiar from novel objects. It critically depends on the integrity of the hippocampus and adjacent cortex. ${ }^{50,91}$ In a previous study, patients with damage limited to the hippocampal region were impaired at both visual and olfactory memory tasks. ${ }^{51}$ The advantage of the social odor novel recognition test is that it uses the rats' primary sensory modality (olfaction) coupled with the social significance (from conspecifics) of the odors to produce strong, long-lasting odor discrimination and memories. ${ }^{90}$ To minimize stress, this test was performed in their familiar home cage environment with conspecific odor without water and food deprivation. Treatment of mTBI with Cerebrolysin improved long-term memory for N1, indicated by rats' preferential exploration of N2 over N1 after a 24-hour delay, which was comparable to the performance by sham rats. Rats with $\mathrm{mTBI}$ receiving saline appeared not to remember $\mathrm{N} 1$ as they showed equal exploration of $\mathrm{N} 1$ and N2. The mechanisms underlying olfactory recognition memory impairment after mTBI remain unclear. The hippocampal CA1 subfield plays an important role in the olfactory behavior in the rat. ${ }^{5,39}$ Our data show that Cerebrolysin significantly reduced APP accumulation and astrocyte activation in several brain regions, including the CA1 subfield.

Cerebrolysin has been used for the treatment of stroke, TBI, and many neurodegenerative diseases in both animal models and patients. 1,6,64,66,79,84,108 The safety of Cerebrolysin has been well established in humans. . $^{2,3,9,27,28,48,82,96,99}$ These findings indicate that Cerebrolysin can be used for reducing and/or reversing cognitive impairment after mTBI. Indeed, a recent clinical trial indicates that Cerebrolysin (starting within 24 hours postinjury for a 5-day treatment) improves the cognitive function of mTBI patients at the third month after injury, especially for memory and drawing functions. ${ }^{8}$

\section{Conclusions}

Cerebrolysin improves long-term spatial and nonspatial cognitive memory in rats after mTBI as demonstrated by the modified MWM test and the novel social odor-based novelty recognition memory test, respectively. Improvement of cognitive memory by Cerebrolysin treatment is at least partly associated with an enhanced number of neuroblasts and newborn mature neurons in the dentate gyrus, reduced diffuse astrocyte activation, and APP accumulation in brain regions after mTBI. These results suggest that Cerebrolysin represents a potential treatment for mTBI.

\section{Acknowledgment}

We would like to thank Susan MacPhee-Gray for her editorial assistance. 


\section{References}

1. Allegri RF, Guekht A: Cerebrolysin improves symptoms and delays progression in patients with Alzheimer's disease and vascular dementia. Drugs Today (Barc) 48 Suppl A:25-41, 2012

2. Alvarez XA, Cacabelos R, Laredo M, Couceiro V, Sampedro C, Varela M, et al: A 24-week, double-blind, placebocontrolled study of three dosages of Cerebrolysin in patients with mild to moderate Alzheimer's disease. Eur J Neurol 13:43-54, 2006

3. Alvarez XA, Cacabelos R, Sampedro C, Aleixandre M, Linares C, Granizo E, et al: Efficacy and safety of Cerebrolysin in moderate to moderately severe Alzheimer's disease: results of a randomized, double-blind, controlled trial investigating three dosages of Cerebrolysin. Eur J Neurol 18:59-68, 2011

4. Beaumont A, Marmarou A, Czigner A, Yamamoto M, Demetriadou K, Shirotani T, et al: The impact-acceleration model of head injury: injury severity predicts motor and cognitive performance after trauma. Neurol Res 21:742-754, 1999

5. Bernal-Mondragón C, Rivas-Arancibia S, Kendrick KM, Guevara-Guzmán R: Estradiol prevents olfactory dysfunction induced by A- $\beta$ 25-35 injection in hippocampus. BMC Neurosci 14:104, 2013

6. Bornstein N, Poon WS: Accelerated recovery from acute brain injuries: clinical efficacy of neurotrophic treatment in stroke and traumatic brain injuries. Drugs Today (Barc) 48 Suppl A:43-61, 2012

7. Bye N, Carron S, Han X, Agyapomaa D, Ng SY, Yan E, et al: Neurogenesis and glial proliferation are stimulated following diffuse traumatic brain injury in adult rats. J Neurosci Res 89:986-1000, 2011

8. Chen CC, Wei ST, Tsaia SC, Chen XX, Cho DY: Cerebrolysin enhances cognitive recovery of mild traumatic brain injury patients: double-blind, placebo-controlled, randomized study. Br J Neurosurg 27:803-807, 2013

9. Chen N, Yang M, Guo J, Zhou M, Zhu C, He L: Cerebrolysin for vascular dementia. Cochrane Database Syst Rev 1:CD008900, 2013

10. Choi SH, Woodlee MT, Hong JJ, Schallert T: A simple modification of the water maze test to enhance daily detection of spatial memory in rats and mice. $\mathbf{J}$ Neurosci Methods 156:182-193, 2006

11. Chopp M, Li Y, Zhang J: Plasticity and remodeling of brain. J Neurol Sci 265:97-101, 2008

12. Chopp M, Li Y,Zhang ZG: Mechanisms underlying improved recovery of neurological function after stroke in the rodent after treatment with neurorestorative cell-based therapies. Stroke 40 (3 Suppl):S143-S145, 2009

13. Corrigan F, Vink R, Blumbergs PC, Masters CL, Cappai R, van den Heuvel C: Characterisation of the effect of knockout of the amyloid precursor protein on outcome following mild traumatic brain injury. Brain Res 1451:87-99, 2012

14. Dancause N, Nudo RJ: Shaping plasticity to enhance recovery after injury. Prog Brain Res 192:273-295, 2011

15. Daneshvar DH, Riley DO, Nowinski CJ, McKee AC, Stern RA, Cantu RC: Long-term consequences: effects on normal development profile after concussion. Phys Med Rehabil Clin N Am 22:683-700, ix, 2011

16. Darwish H, Mahmood A, Schallert T, Chopp M, Therrien B: Mild traumatic brain injury (MTBI) leads to spatial learning deficits. Brain Inj 26:151-165, 2012 (Erratum in Brain Inj 26:1763, 2012)

17. Dean PJ, Sterr A: Long-term effects of mild traumatic brain injury on cognitive performance. Front Hum Neurosci 7:30, 2013

18. Dewitt DS, Perez-Polo R, Hulsebosch CE, Dash PK, Robertson CS: Challenges in the development of rodent models of mild traumatic brain injury. J Neurotrauma 30:688-701, 2013
19. D'Hooge R, De Deyn PP: Applications of the Morris water maze in the study of learning and memory. Brain Res Brain Res Rev 36:60-90, 2001

20. Eriksson PS, Perfilieva E, Björk-Eriksson T, Alborn AM, Nordborg C, Peterson DA, et al: Neurogenesis in the adult human hippocampus. Nat Med 4:1313-1317, 1998

21. Foda MA, Marmarou A: A new model of diffuse brain injury in rats. Part II: Morphological characterization. J Neurosurg 80:301-313, 1994

22. Gao X, Chen J: Mild traumatic brain injury results in extensive neuronal degeneration in the cerebral cortex. J Neuropathol Exp Neurol 70:183-191, 2011

23. Gatson JW, Liu MM, Abdelfattah K, Wigginton JG, Smith S, Wolf S, et al: Resveratrol decreases inflammation in the brain of mice with mild traumatic brain injury. J Trauma Acute Care Surg 74:470-475, 2013

24. Haber M, Abdel Baki SG, Grin'kina NM, Irizarry R, Ershova A, Orsi S, et al: Minocycline plus N-acetylcysteine synergize to modulate inflammation and prevent cognitive and memory deficits in a rat model of mild traumatic brain injury. Exp Neurol 249:169-177, 2013

25. Hamm RJ, Lyeth BG, Jenkins LW, O'Dell DM, Pike BR: Selective cognitive impairment following traumatic brain injury in rats. Behav Brain Res 59:169-173, 1993

26. Hampson RE, Simeral JD, Deadwyler SA: Distribution of spatial and nonspatial information in dorsal hippocampus. Nature 402:610-614, 1999

27. Heiss WD, Brainin M, Bornstein NM, Tuomilehto J, Hong Z: Cerebrolysin in patients with acute ischemic stroke in Asia: results of a double-blind, placebo-controlled randomized trial. Stroke 43:630-636, 2012

28. Hong Z, Moessler H, Bornstein N, Brainin M, Heiss WD: A double-blind, placebo-controlled, randomized trial to evaluate the safety and efficacy of Cerebrolysin in patients with acute ischaemic stroke in Asia-CASTA. Int J Stroke 4:406-412, 2009

29. Hortobágyi T, Wise S, Hunt N, Cary N, Djurovic V, FeganEarl A, et al: Traumatic axonal damage in the brain can be detected using beta-APP immunohistochemistry within 35 min after head injury to human adults. Neuropathol Appl Neurobiol 33:226-237, 2007

30. Israelsson C, Wang Y, Kylberg A, Pick CG, Hoffer BJ, Ebendal T: Closed head injury in a mouse model results in molecular changes indicating inflammatory responses. J Neurotrauma 26:1307-1314, 2009

31. Itoh T, Satou T, Nishida S, Tsubaki M, Hashimoto S, Ito H: Expression of amyloid precursor protein after rat traumatic brain injury. Neurol Res 31:103-109, 2009

32. Johnson VE, Stewart JE, Begbie FD, Trojanowski JQ, Smith $\mathrm{DH}$, Stewart W: Inflammation and white matter degeneration persist for years after a single traumatic brain injury. Brain 136:28-42, 2013

33. Johnson VE, Stewart W, Smith DH: Axonal pathology in traumatic brain injury. Exp Neurol 246:35-43, 2013

34. Johnson VE, Stewart W, Smith DH: Widespread tau and amyloid-beta pathology many years after a single traumatic brain injury in humans. Brain Pathol 22:142-149, 2012

35. Kallakuri S, Cavanaugh JM, Ozaktay AC, Takebayashi T: The effect of varying impact energy on diffuse axonal injury in the rat brain: a preliminary study. Exp Brain Res 148:419-424, 2003

36. Kee N, Teixeira CM, Wang AH, Frankland PW: Imaging activation of adult-generated granule cells in spatial memory. Nat Protoc 2:3033-3044, 2007

37. Kee N, Teixeira CM, Wang AH, Frankland PW: Preferential incorporation of adult-generated granule cells into spatial memory networks in the dentate gyrus. Nat Neurosci 10:355-362, 2007

38. Kerr AL, Cheng SY, Jones TA: Experience-dependent neural 
plasticity in the adult damaged brain. J Commun Disord 44:538-548, 2011

39. Kesner RP, Hunsaker MR, Ziegler W: The role of the dorsal CA1 and ventral CA1 in memory for the temporal order of a sequence of odors. Neurobiol Learn Mem 93:111-116, 2010

40. Kitabatake Y, Sailor KA, Ming GL, Song H: Adult neurogenesis and hippocampal memory function: new cells, more plasticity, new memories? Neurosurg Clin N Am 18:105$113, x, 2007$

41. Kleim JA: Neural plasticity and neurorehabilitation: teaching the new brain old tricks. J Commun Disord 44:521-528, 2011

42. Koehl M, Abrous DN: A new chapter in the field of memory: adult hippocampal neurogenesis. Eur J Neurosci 33:11011114, 2011

43. Kögel D, Deller T, Behl C: Roles of amyloid precursor protein family members in neuroprotection, stress signaling and aging. Exp Brain Res 217:471-479, 2012

44. Kohler SJ, Williams NI, Stanton GB, Cameron JL, Greenough WT: Maturation time of new granule cells in the dentate gyrus of adult macaque monkeys exceeds six months. Proc Natl Acad Sci U S A 108:10326-10331, 2011

45. Kuhn HG, Dickinson-Anson H, Gage FH: Neurogenesis in the dentate gyrus of the adult rat: age-related decrease of neuronal progenitor proliferation. J Neurosci 16:2027-2033, 1996

46. Kumaran D, Hassabis D, Spiers HJ, Vann SD, VarghaKhadem F, Maguire EA: Impaired spatial and non-spatial configural learning in patients with hippocampal pathology. Neuropsychologia 45:2699-2711, 2007

47. Laird MD, Vender JR, Dhandapani KM: Opposing roles for reactive astrocytes following traumatic brain injury. Neurosignals 16:154-164, 2008

48. Lang W, Stadler CH, Poljakovic Z, Fleet D: A prospective, randomized, placebo-controlled, double-blind trial about safety and efficacy of combined treatment with alteplase (rtPA) and Cerebrolysin in acute ischaemic hemispheric stroke. Int J Stroke 8:95-104, 2013

49. Lapchak PA, Zhang JH, Noble-Haeusslein LJ: RIGOR guidelines: escalating STAIR and STEPS for effective translational research. Transl Stroke Res 4:279-285, 2013

50. Levy DA, Hopkins RO, Squire LR: Impaired odor recognition memory in patients with hippocampal lesions. Learn Mem 11:794-796, 2004

51. Levy DA, Manns JR, Hopkins RO, Gold JJ, Broadbent NJ, Squire LR: Impaired visual and odor recognition memory span in patients with hippocampal lesions. Learn Mem 10:531-536, 2003

52. Li S, Kuroiwa T, Ishibashi S, Sun L, Endo S, Ohno K: Transient cognitive deficits are associated with the reversible accumulation of amyloid precursor protein after mild traumatic brain injury. Neurosci Lett 409:182-186, 2006

53. Liu P, Li YS, Quartermain D, Boutajangout A, Ji Y: Inhaled nitric oxide improves short term memory and reduces the inflammatory reaction in a mouse model of mild traumatic brain injury. Brain Res 1522:67-75, 2013

54. Livingstone SA, Skelton RW: Virtual environment navigation tasks and the assessment of cognitive deficits in individuals with brain injury. Behav Brain Res 185:21-31, 2007

55. Loane DJ, Faden AI: Neuroprotection for traumatic brain injury: translational challenges and emerging therapeutic strategies. Trends Pharmacol Sci 31:596-604, 2010

56. Lu D, Mahmood A, Zhang R, Copp M: Upregulation of neurogenesis and reduction in functional deficits following administration of DEtA/NONOate, a nitric oxide donor, after traumatic brain injury in rats. J Neurosurg 99:351-361, 2003

57. Lu J, Gary KW, Neimeier JP, Ward J, Lapane KL: Randomized controlled trials in adult traumatic brain injury. Brain Inj 26:1523-1548, 2012
58. Mahmood A, Lu D, Qu C, Goussev A, Chopp M: Treatment of traumatic brain injury with a combination therapy of marrow stromal cells and atorvastatin in rats. Neurosurgery 60:546-554, 2007

59. Marín-Burgin A, Schinder AF: Requirement of adult-born neurons for hippocampus-dependent learning. Behav Brain Res 227:391-399, 2012

60. Markakis EA, Gage FH: Adult-generated neurons in the dentate gyrus send axonal projections to field CA3 and are surrounded by synaptic vesicles. J Comp Neurol 406:449-460, 1999

61. Marklund N, Farrokhnia N, Hånell A, Vanmechelen E, Enblad P, Zetterberg H, et al: Monitoring of $\beta$-amyloid dynamics after human traumatic brain injury. $\mathbf{J}$ Neurotrauma 31:42-55, 2014

62. Marmarou A, Foda MA, van den Brink W, Campbell J, Kita $\mathrm{H}$, Demetriadou K: A new model of diffuse brain injury in rats. Part I: Pathophysiology and biomechanics. J Neurosurg 80:291-300, 1994

63. Marmarou CR, Walker SA, Davis CL, Povlishock JT: Quantitative analysis of the relationship between intra- axonal neurofilament compaction and impaired axonal transport following diffuse traumatic brain injury. J Neurotrauma 22:1066-1080, 2005

64. Masliah E, Diez-Tejedor E: The pharmacology of neurotrophic treatment with Cerebrolysin: brain protection and repair to counteract pathologies of acute and chronic neurological disorders. Drugs Today (Barc) 48 Suppl A:3-24, 2012

65. Meng Y, Xiong Y, Mahmood A, Zhang Y, Qu C, Chopp M: Dose-dependent neurorestorative effects of delayed treatment of traumatic brain injury with recombinant human erythropoietin in rats. J Neurosurg 115:550-560, 2011

66. Menon PK, Muresanu DF, Sharma A, Mössler H, Sharma HS: Cerebrolysin, a mixture of neurotrophic factors induces marked neuroprotection in spinal cord injury following intoxication of engineered nanoparticles from metals. CNS Neurol Disord Drug Targets 11:40-49, 2012

67. Milman A, Rosenberg A, Weizman R, Pick CG: Mild traumatic brain injury induces persistent cognitive deficits and behavioral disturbances in mice. J Neurotrauma 22:10031010,2005

68. Ming GL, Song H: Adult neurogenesis in the mammalian central nervous system. Annu Rev Neurosci 28:223-250, 2005

69. Monti JM, Voss MW, Pence A, McAuley E, Kramer AF, Cohen NJ: History of mild traumatic brain injury is associated with deficits in relational memory, reduced hippocampal volume, and less neural activity later in life. Front Aging Neurosci 5:41, 2013

70. Morris RG, Garrud P, Rawlins JN, O'Keefe J: Place navigation impaired in rats with hippocampal lesions. Nature 297:681-683, 1982

71. Mouzon BC, Bachmeier C, Ferro A, Ojo JO, Crynen G, Acker CM, et al: Chronic neuropathological and neurobehavioral changes in a repetitive mild traumatic brain injury model. Ann Neurol 75:241-254, 2014

72. Myer DJ, Gurkoff GG, Lee SM, Hovda DA, Sofroniew MV: Essential protective roles of reactive astrocytes in traumatic brain injury. Brain 129:2761-2772, 2006

73. Namjoshi DR, Good C, Cheng WH, Panenka W, Richards D, Cripton PA, et al: Towards clinical management of traumatic brain injury: a review of models and mechanisms from a biomechanical perspective. Dis Model Mech 6:1325-1338, 2013

74. Newcombe VF, Menon DK: Cognitive deficits and mild traumatic brain injury. BMJ 346:f1522, 2013

75. Ngwenya LB, Peters A, Rosene DL: Maturational sequence of newly generated neurons in the dentate gyrus of the young adult rhesus monkey. J Comp Neurol 498:204-216, 2006 
76. Nudo RJ: Neural bases of recovery after brain injury. J Commun Disord 44:515-520, 2011

77. O'Dell SJ, Feinberg LM, Marshall JF: A neurotoxic regimen of methamphetamine impairs novelty recognition as measured by a social odor-based task. Behav Brain Res 216:396-401, 2011

78. Paxinos G, Watson C: The Rat Brain in Stereotaxic Coordinates, ed 2. Orlando, FL: Academic Press, 1986

79. Plosker GL, Gauthier S: Cerebrolysin: a review of its use in dementia. Drugs Aging 26:893-915, 2009

80. Rockenstein E, Mante M, Adame A, Crews L, Moessler H, Masliah E: Effects of Cerebrolysin on neurogenesis in an APP transgenic model of Alzheimer's disease. Acta Neuropathol 113:265-275, 2007

81. Rockenstein E, Torrance M, Mante M, Adame A, Paulino A, Rose JB, et al: Cerebrolysin decreases amyloid-beta production by regulating amyloid protein precursor maturation in a transgenic model of Alzheimer's disease. J Neurosci Res 83:1252-1261, 2006

82. Ruether E, Husmann R, Kinzler E, Diabl E, Klingler D, Spatt J, et al: A 28-week, double-blind, placebo-controlled study with Cerebrolysin in patients with mild to moderate Alzheimer's disease. Int Clin Psychopharmacol 16:253-263, 2001

83. Shapira M, Licht A, Milman A, Pick CG, Shohami E, EldarFinkelman H: Role of glycogen synthase kinase-3beta in early depressive behavior induced by mild traumatic brain injury. Mol Cell Neurosci 34:571-577, 2007

84. Sharma A, Muresanu DF, Mössler H, Sharma HS: Superior neuroprotective effects of cerebrolysin in nanoparticle-induced exacerbation of hyperthermia-induced brain pathology. CNS Neurol Disord Drug Targets 11:7-25, 2012

85. Sharma HS, Zimmermann-Meinzingen S, Johanson CE: Cerebrolysin reduces blood-cerebrospinal fluid barrier permeability change, brain pathology, and functional deficits following traumatic brain injury in the rat. Ann N Y Acad Sci 1199:125-137, 2010

86. Signoretti S, Di Pietro V, Vagnozzi R, Lazzarino G, Amorini AM, Belli A, et al: Transient alterations of creatine, creatine phosphate, $\mathrm{N}$-acetylaspartate and high-energy phosphates after mild traumatic brain injury in the rat. Mol Cell Biochem 333:269-277, 2010

87. Smith DH, Okiyama K, Thomas MJ, Claussen B, McIntosh TK: Evaluation of memory dysfunction following experimental brain injury using the Morris water maze. J Neurotrauma 8:259-269, 1991

88. Sofroniew MV: Reactive astrocytes in neural repair and protection. Neuroscientist 11:400-407, 2005

89. Spalding KL, Bergmann O, Alkass K, Bernard S, Salehpour M, Huttner HB, et al: Dynamics of hippocampal neurogenesis in adult humans. Cell 153:1219-1227, 2013

90. Spinetta MJ, Woodlee MT, Feinberg LM, Stroud C, Schallert $\mathrm{K}$, Cormack LK, et al: Alcohol-induced retrograde memory impairment in rats: prevention by caffeine. Psychopharmacology (Berl) 201:361-371, 2008

91. Squire LR, Stark CE, Clark RE: The medial temporal lobe. Annu Rev Neurosci 27:279-306, 2004

92. Sun D, Colello RJ, Daugherty WP, Kwon TH, McGinn MJ, Harvey HB, et al: Cell proliferation and neuronal differentiation in the dentate gyrus in juvenile and adult rats following traumatic brain injury. J Neurotrauma 22:95-105, 2005

93. Tashlykov V, Katz Y, Volkov A, Gazit V, Schreiber S, Zohar $\mathrm{O}$, et al: Minimal traumatic brain injury induce apoptotic cell death in mice. J Mol Neurosci 37:16-24, 2009

94. Tay SY, Ang BT, Lau XY, Meyyappan A, Collinson SL: Chronic impairment of prospective memory after mild traumatic brain injury. J Neurotrauma 27:77-83, 2010

95. Terry AV Jr: Spatial navigation (water maze) tasks, in Buccafusco JJ (ed): Behavioral Methods in Neuroscience. Boca Raton, FL: CRC Press, 2009, pp 153-166
96. Thome J, Doppler E: Safety profile of Cerebrolysin: clinical experience from dementia and stroke trials. Drugs Today (Barc) 48 Suppl A:63-69, 2012

97. Ubhi K, Rockenstein E, Doppler E, Mante M, Adame A, Patrick C, et al: Neurofibrillary and neurodegenerative pathology in APP-transgenic mice injected with AAV2mutant TAU: neuroprotective effects of Cerebrolysin. Acta Neuropathol 117:699-712, 2009

98. Vukovic J, Borlikova GG, Ruitenberg MJ, Robinson GJ, Sullivan RK, Walker TL, et al: Immature doublecortinpositive hippocampal neurons are important for learning but not for remembering. J Neurosci 33:6603-6613, 2013

99. Xiao S, Xue H, Li G, Yuan C, Li X, Chen C, et al: Therapeutic effects of cerebrolysin added to risperidone in patients with schizophrenia dominated by negative symptoms. Aust N Z J Psychiatry 46:153-160, 2012

100. Xiong Y, Mahmood A, Meng Y, Zhang Y, Zhang ZG, Morris DC, et al: Treatment of traumatic brain injury with thymosin $\beta_{4}$ in rats. J Neurosurg 114:102-115, 2011

101. Yang SH, Gustafson J, Gangidine M, Stepien D, Schuster $\mathrm{R}$, Pritts TA, et al: A murine model of mild traumatic brain injury exhibiting cognitive and motor deficits. J Surg Res 184:981-988, 2013

102. Zhang C, Chopp M, Cui Y, Wang L, Zhang R, Zhang L, et al: Cerebrolysin enhances neurogenesis in the ischemic brain and improves functional outcome after stroke. J Neurosci Res 88:3275-3281, 2010

103. Zhang L, Chopp M, Meier DH, Winter S, Wang L, Szalad A, et al: Sonic hedgehog signaling pathway mediates cerebrolysin-improved neurological function after stroke. Stroke 44:1965-1972, 2013

104. Zhang R, Wang Y, Zhang L, Zhang Z, Tsang W, Lu M, et al: Sildenafil (Viagra) induces neurogenesis and promotes functional recovery after stroke in rats. Stroke 33:26752680,2002

105. Zhang Y, Chopp M, Meng Y, Zhang ZG, Doppler E, Mahmood A, et al: Improvement in functional recovery with administration of Cerebrolysin after experimental closed head injury. J Neurosurg 118:1343-1355, 2013

106. Zhang ZG, Chopp M: Neurorestorative therapies for stroke: underlying mechanisms and translation to the clinic. Lancet Neurol 8:491-500, 2009

107. Zhao C, Deng W, Gage FH: Mechanisms and functional implications of adult neurogenesis. Cell 132:645-660, 2008

108. Ziganshina LE, Abakumova T, Kuchaeva A: Cerebrolysin for acute ischaemic stroke. Cochrane Database Syst Rev (4):CD007026, 2010

109. Zohar O, Lavy R, Zi X, Nelson TJ, Hongpaisan J, Pick CG, et al: PKC activator therapeutic for mild traumatic brain injury in mice. Neurobiol Dis 41:329-337, 2011

110. Zohar O, Rubovitch V, Milman A, Schreiber S, Pick CG: Behavioral consequences of minimal traumatic brain injury in mice. Acta Neurobiol Exp (Warsz) 71:36-45, 2011

\section{Author Contributions}

Conception and design: Xiong, Chopp, ZG Zhang. Acquisition of data: Xiong, Y Zhang, Meng. Analysis and interpretation of data: Xiong, Y Zhang, Chopp, Meng, ZG Zhang, Doppler, Schallert, Mahmood. Drafting the article: Xiong, Y Zhang. Critically revising the article: Xiong, Chopp, ZG Zhang, Doppler, Winter. Reviewed submitted version of manuscript: all authors. Approved the final version of the manuscript on behalf of all authors: Xiong.

\section{Correspondence}

Ye Xiong, Department of Neurosurgery, Henry Ford Health System, E\&R Building, Rm. 3096, 2799 W. Grand Blvd., Detroit, MI 48202. email: yxiong1@hfhs.org. 